\title{
Effects of positive end expiratory pressure during ventilation of the preterm infant
}

\author{
D FIELD, A D MILNER, AND I E HOPKIN \\ Department of Neonatal Medicine and Surgery, City Hospital, Nottingham
}

SUMMARY Twenty two babies receiving artificial ventilator support were studied on 29 occasions to determine the effects of low levels of positive end expiratory pressure. Mean positive end expiratory pressure during these studies was $2.6 \mathrm{~cm} \mathrm{H}_{2} \mathrm{O}$. Changes in tidal volume, minute volume, compliance, and transcutaneous gas trends produced by the use of positive end expiratory pressure were investigated. Positive end expiratory pressure consistently caused a rise in transcutaneous oxygen tension. Changes in transcutaneous carbon dioxide tension after the introduction of positive end expiratory pressure were less consistent and not of the same magnitude as the observed reduction in minute ventilation. Compliance values fell with the use of positive end expiratory pressure.

Positive end expiratory pressure has been a standard technique for improving the oxygenation of ventilator dependent infants since Herman and Reynolds ${ }^{1}$ described its beneficial effects in neonates with idiopathic respiratory distress syndrome. In the intervening 10 years, further work has confirmed that positive end expiratory pressure probably exerts its effects on oxygenation by raising mean airways pressure. ${ }^{2}$ It has also been shown to be more efficient in producing a rise in arterial oxygen tension $\left(\mathrm{PaO}_{2}\right)$ for a given increase in mean airways pressure than increasing inspiratory to expiratory ratios. $^{3}$

Herman and Reynolds ${ }^{1}$ also noticed that positive end expiratory pressure produced a rise in arterial carbon dioxide tension $\mathrm{PaCO}_{2}$ which they felt was the result of a reduction in tidal volume and relative hypoventilation. Measurements supporting this hypothesis were made on the excised lungs of babies who had died from idiopathic respiratory distress syndrome. These measurements showed the presence of an inspiratory opening pressure of 10 to 15 $\mathrm{cm} \mathrm{H}_{2} \mathrm{O}$ which could be abolished or reduced by the use of an end expiratory pressure. ${ }^{45}$

Increasing awareness of both the morbidity associated with the use of ventilators in the newborn and of the changing pattern of neonatal respiratory disease away from classic idiopathic respiratory distress syndrome has led to the use of lower levels of positive end expiratory pressure than in the early $1970 \mathrm{~s}$. We decided, therefore, to review the role of positive end expiratory pressure as it is currently applied, in terms of its effect on gas exchange and on effective ventilation.

\section{Subjects and methods}

Subjects. Twenty nine studies were performed on 22 babies, 15 (21 studies) of whom were diagnosed as having idiopathic respiratory distress syndrome and seven (eight studies) of whom were being ventilated for problems relating to apnoea of prematurity. Ventilator rates ranged from 17 to 100 breaths per minute (mean 54). No babies were sedated or paralysed.

Details of the babies are given in Table 1. All babies were ventilated on Draeger Babylog infant ventilators (time cycled pressure limited). Portex shouldered endotracheal tubes were used (size $2 \cdot 5$ or $3.0 \mathrm{~mm}$ ) in all studies. Gas leak around the shouldered endotracheal tubes was not present in any study.

Table 1 Details of 22 babies included in the study

\begin{tabular}{lcll}
\hline Diagnosis & No & $\begin{array}{l}\text { Birthweight }(\mathrm{kg}) \\
\text { Mean (range) }\end{array}$ & $\begin{array}{l}\text { Gestation (wks) } \\
\text { Mean (range) }\end{array}$ \\
\hline $\begin{array}{l}\text { Idiopathic respiratory } \\
\text { distress syndrome }\end{array}$ & 15 & $1.6(0.99-2.4)$ & $31.7(29-40)$ \\
\hline Apnoea of prematurity & 7 & $0.89(0.68-1.02)$ & $26.9(24-29)$ \\
\hline
\end{tabular}


Apparatus. Measurements were performed as follows:

(1) Inflation pressure-a wide bore needle was inserted into the infant's endotracheal tube at the point where it entered the mouth and connected to a South East Laboratories' 4.86 pressure transducer. Calibration was performed using a water manometer. Frequency response, measured by bursting balloons in a sealed bottle to which the pressure transducer was connected, was satisfactory with a $63 \%$ rise time of 6 milliseconds.

(2) Oesophageal pressure-an oesophageal balloon was passed using standard techniques and connected to a pressure transducer calibrated as above. Signals obtained were used only to provide a qualitative estimate of the infant's respiratory efforts.

(3) Tidal volume-a Fleisch type O pneumotachograph was connected between the patient manifold of the venilator circuit and the endo tracheal tube. A constant bias flow through the pneumotachograph was achieved by connecting a suction pump (Airshields Diapump) via a 21 gauge needle between the distal portion of the pneumotachograph and the infant's endotracheal tube. As the pressure gradient across the needle was in the order of $900 \mathrm{~cm} \mathrm{H}_{2} \mathrm{O}$, the bias flow was not affected by the ventilator cycling pressure. Provided that the ventilator circuit was compensated for the loss of the bias flow, ventilator performance was not affected. The flow signal was converted to a volume signal by electronic integration against time. Calibration was performed by injecting and withdrawing known volumes of air. The pneumotachograph was found to give a linear response at flows up to $30 \mathrm{l} /$ minute. The $63 \%$ rise time of the pneumotachograph, tubes, and differential pressure transducer was $10 \cdot 3$ milliseconds. The use of a transducer/ pneumo tachograph/integrator to measure tidal volume may lead to errors in calculation when employed in a pressurised system. Errors will occur if there is any difference in the time constants of the two sides of the pneumotachograph/pressure transducer apparatus. We eliminated this problem by ensuring that the two sides of the system were correctly balanced. As a further check we occluded the pneumotachograph, rapidly raised the internal pressure, and then confirmed that no flow had been recorded during the manoeuvre.

(4) Blood gases-blood gas trends were recorded with a Radiometer $\mathrm{TcPo}_{2}$ and $\mathrm{TcPCO}$ apparatus. These were used over the period of the study to provide a measure of change; ${ }^{67}$ however values were always checked against an arterial blood gas sample taken during the course of the study.

Tidal volume and pressure signals were both displayed during collection of data on a Devices 2 channel recorder. Inflation pressure and tidal volume signals were analysed by a Commodore 4032 computer using a respiratory function programme described previously ${ }^{8}$ and modified to accept a positive inflation pressure. Calculated mean values were obtained for:

(1) Tidal volume;

(2) Inflation pressure;

(3) Minute volume;

(4) Rate;

(5) 'Compliance'; this was derived by the com puter using the mean of the inspiratory and expiratory volume and pressure signals. This value should represent a true measure of lung stiffness in those studies in which the baby is not breathing and in which inflation time is sufficiently long to allow tidal volume to plateau.

All calculated values represent the mean of breaths occurring over at least 30 seconds. Where spontaneous respiration prevented any computer analysis, calculation of tidal volume, inflation pressure, minute volume, and rate was made from the paper trace using a similar number of breaths.

In addition, at each setting we also derived mean airways pressure (measured direct from the paper trace) and effective ventilation (calculated by subtracting an estimated dead space of $2.2 \mathrm{ml} / \mathrm{kg}$ from the tidal volume. This value is an approximation using information from infants who had not been intubated).

Methods. Each baby was studied by DF and IH. At the start of each study the pneumotachograph was inserted into the ventilator circuit, the inflation pressure transducer connected into the endotracheal tube, the oesophageal ballon passed, and transcutaneous electrodes attached to suitable sites on the child's chest or abdomen. A period of at least 15 minutes then elapsed while the transcutaneous readings stabilised. The only manoeuvre carried out during the stabilisation period was to apply a sustained five second inflation. It was possible to detect any leak around the endotracheal tube by a failure of the volume signal to reach a plateau either during this manoeuvre or after release of the inflation pressure. At the end of the period of stabilisation, the first 14 minute study period commenced, during which 30 seconds of inflation pressure and tidal volume signals were fed via an analogue to digital converter into the computer and transcutaneous gas values were recorded at 2 minute intervals. If on its initial settings, the infant had been receiving no positive end expiratory pressure as recorded clinically from the ventilator display during the second study period, this level was then altered 
to a $3 \mathrm{~cm} \mathrm{H}_{2} \mathrm{O}$, as determined by the ventilator dial. The ventilator settings were otherwise left unaltered. Lung function measurements were then repeated during a 14 minute period of obversation, transcutaneous readings being recorded at two minute intervals. If necessary this period was extended to allow transcutaneous values to stabilise. If the baby's original settings included positive end expiratory pressure then the studies were performed in the reverse order starting with the original level of positive end expiratory pressure.

Since the Babylog ventilator has a constant gas flow some positive end expiratory pressure is inevitable. The shift in end tidal pressure during a brief disconnection of the ventilator circuit was used to determine the true level of positive end expiratory pressure at each setting. This was achieved by opening the suction port of the ventilator patient manifold for three to five seconds. As a result the inflation pressure signal as recorded on paper fell to atmospheric pressure. It was then possible to measure the difference between the previous end tidal point reached during ventilation and atmospheric pressure.

We excluded all studies in which there was a change in peak pressure as a result of our manoeuvres, or in which positive end expiratory pressure could not be reduced to less than $1 \mathrm{~cm} \mathrm{H}_{2} \mathrm{O}$.

\section{Results}

In 20 studies (15 in infants with idiopathic respiratory distress syndrome and five in infants ventilated for apnoea of prematurity) the infants were making no spontaneous respiratory efforts. Ten of these babies had had positive end expiratory pressure included in their initial settings and 10 had only minimum positive end expiratory pressure when first measured. Details of changes in mean airways pressure, tidal volume, minute volume, effective minute ventilation, $\mathrm{TcPO}_{2}$ and $\mathrm{TcPCO}_{2}$ for these infants are shown in Table 2. The mean standard errors for measurement of inflation pressure and tidal volume in the group with idiopathic respiratory distress during minimum positive end expiratory pressure were $0.04 \mathrm{~cm} \mathrm{H}_{2} \mathrm{O}$ and $0.16 \mathrm{ml}$ respectively; during positive end expiratory pressure volumes were $0.04 \mathrm{~cm} \mathrm{H}_{2} \mathrm{O}$ and $0.15 \mathrm{ml}$ respectively. In the apnoea of prematurity group, mean standard errors for inflation pressure and tidal volume during minimum positive end expiratory pressure were $0.01 \mathrm{~cm} \mathrm{H}_{2} \mathrm{O}$ and $0.18 \mathrm{ml}$ respectively; during positive end expiratory pressure values were $0.01 \mathrm{~cm} \mathrm{H}_{2} \mathrm{O}$ and $0.08 \mathrm{ml}$ respectively.

In four of these studies on babies with respiratory distress syndrome, a dramatic fall in $\mathrm{TcPo}_{2}$ accompanied the reduction of positive end expiratory pressure to minimum. Stable values for transcutaneous gases could not be obtained at these settings without an increase in inspired oxygen. The $\mathrm{TcPO}_{2}$ value used to calculate a mean for the respiratory distress syndrome group at minimum positive end expiratory pressure was the lowest $\mathrm{TcPO}_{2}$ measured before the inspired oxygen was increased. The mean is therefore an underestimate of the true fall. Transcutaneous $\mathrm{Po}_{2}$ rose by $5 \%$ or more in 14 of the 20 studies after the introduction of positive end expiratory pressure. Transcutaneous $\mathrm{PCO}_{2}$ rose by $5 \%$ or more in nine of the 20 studies. This increase is less than one would have predicted either from the fall in minute volume or effective ventilation. (Table 2).

Compliance values were also calculated in the 20 studies during which there was no spontaneous breathing. A consistent trend was found towards reduced compliance during ventilation with positive end expiratory pressure. For the group of 20 infants as a whole, compliance fell on 15 occasions and was unchanged in the remainder (mean compliance for 20 studies during positive end expiratory pressure $0.57 \mathrm{ml} / \mathrm{cm} \mathrm{H}_{2} \mathrm{O}$; mean compliance during minimum positive end expiratory pressure $0.65 \mathrm{ml} / \mathrm{cm} \mathrm{H}_{2} \mathrm{O}$; $\mathrm{P}=0.001$ paired $t$ test). The mean standard error for compliance measurements during both positive end expiratory pressure and minimum positive end expiratory pressure was $0.01 \mathrm{ml} / \mathrm{cm} \mathrm{H}_{2} \mathrm{O}$.

Table 2 Results of changes in mean airways pressure (MAP), tidal volume, minute volume, effective ventilation, and transcutaneous oxygen and carbon dioxide tensions $\left(\mathrm{TcPo}_{2}, \quad \mathrm{TcPCO}_{2}\right)$, and compliance at each level of positive end expiratory pressure (PEEP) in those babies who were not breathing spontaneously

\begin{tabular}{|c|c|c|c|c|c|c|c|c|c|}
\hline Diagnosis & No & $\begin{array}{l}\text { PEEP } \\
\text { pressure } \\
\left(\mathrm{cm} \mathrm{H}_{2} \mathrm{O}\right)\end{array}$ & $\begin{array}{l}\mathrm{MAP} \\
\left(\mathrm{cm} \mathrm{H}_{2} \mathrm{O}\right)\end{array}$ & $\begin{array}{l}\text { Tidal } \\
\text { volume } \\
(\mathrm{ml})\end{array}$ & $\begin{array}{l}\text { Minute } \\
\text { volume } \\
\text { (ml) }\end{array}$ & $\begin{array}{l}\text { Effective } \\
\text { minute } \\
\text { ventilation } \\
(\mathrm{ml})\end{array}$ & $\begin{array}{l}\mathrm{TcPo}_{2} \\
(\mathrm{~mm} \mathrm{Hg})\end{array}$ & $\begin{array}{l}\mathrm{TcPcO} \\
(\mathrm{mm} \mathrm{Hg})\end{array}$ & $\begin{array}{l}\text { Compliance } \\
\left(\mathrm{ml} / \mathrm{cm} \mathrm{H}_{2} \mathrm{O}\right)\end{array}$ \\
\hline $\begin{array}{l}\text { Idiopathic respiratory } \\
\text { distress syndrome }\end{array}$ & 15 & $\begin{array}{l}0 \cdot 7 \\
2 \cdot 5\end{array}$ & $\begin{array}{l}10 \cdot 1 \\
11 \cdot 4\end{array}$ & $\begin{array}{r}11 \cdot 8 \\
9 \cdot 3\end{array}$ & $\begin{array}{l}814 \\
686\end{array}$ & $\begin{array}{l}710 \\
580\end{array}$ & $\begin{array}{l}46 \\
52\end{array}$ & $\begin{array}{l}52 \\
55\end{array}$ & $\begin{array}{l}0.68 \\
0.62\end{array}$ \\
\hline Apnoea of prematurity & 5 & $\begin{array}{l}0.7 \\
2.8\end{array}$ & $\begin{array}{l}7 \cdot 3 \\
9\end{array}$ & $\begin{array}{l}9.9 \\
7.5\end{array}$ & $\begin{array}{l}360 \\
252\end{array}$ & $\begin{array}{l}284 \\
178\end{array}$ & $\begin{array}{l}62 \\
76\end{array}$ & $\begin{array}{l}42 \\
48\end{array}$ & $\begin{array}{l}0.56 \\
0.44\end{array}$ \\
\hline
\end{tabular}


Table 3 Results of changes in mean airways pressure (MAP), tidal volume, minute volume, effective ventilation, and transcutaneous oxygen and carbon dioxide tensions $\left(\mathrm{TcPO}_{2}, \mathrm{TcPCO}_{2}\right)$ at each level of positive end expiratory pressure (PEEP) in babies making spontaneous respiratory efforts

\begin{tabular}{|c|c|c|c|c|c|c|c|c|}
\hline Diagnosis & No & $\begin{array}{l}\text { PEEP } \\
\text { pressure } \\
\left(\mathrm{cm} \mathrm{H}_{2} \mathrm{O}\right)\end{array}$ & $\begin{array}{l}\mathrm{MAP} \\
\left(\mathrm{cm} \mathrm{H}_{2} \mathrm{O}\right)\end{array}$ & $\begin{array}{l}\text { Tidal } \\
\text { volume }(\mathrm{ml})\end{array}$ & $\begin{array}{l}\text { Minute } \\
\text { volume }(\mathrm{ml})\end{array}$ & $\begin{array}{l}\text { Effective } \\
\text { minute } \\
\text { volume }(\mathrm{ml})\end{array}$ & $\begin{array}{l}\mathrm{TcPo}_{2} \\
(\mathrm{~mm} \mathrm{Hg})\end{array}$ & $\begin{array}{l}\mathrm{TcPcO}_{2} \\
(\mathrm{~mm} \mathrm{Hg})\end{array}$ \\
\hline $\begin{array}{l}\text { Idiopathic respiratory } \\
\text { distress syndrome }\end{array}$ & 6 & $\begin{array}{l}0 \cdot 5 \\
2 \cdot 8\end{array}$ & $\begin{array}{l}4 \cdot 8 \\
6 \cdot 9\end{array}$ & $\begin{array}{r}12 \cdot 4 \\
9 \cdot 8\end{array}$ & $\begin{array}{l}423 \\
364\end{array}$ & $\begin{array}{l}343 \\
280\end{array}$ & $\begin{array}{l}53 \\
63\end{array}$ & $\begin{array}{l}60 \\
65\end{array}$ \\
\hline Apnoea of prematurity & 3 & $\begin{array}{l}0 \cdot 6 \\
2 \cdot 6\end{array}$ & $\begin{array}{l}3 \cdot 0 \\
5\end{array}$ & $\begin{array}{l}13.3 \\
11.6\end{array}$ & $\begin{array}{l}276 \\
207\end{array}$ & $\begin{array}{l}207 \\
157\end{array}$ & $\begin{array}{l}58 \\
65\end{array}$ & $\begin{array}{l}41 \\
41\end{array}$ \\
\hline
\end{tabular}

In nine studies (six in babies with respiratory distress and three in babies with apnoea) babies were making active respiratory efforts, and the results are shown in Table 3 . Trends are in keeping with the group in which we observed no spontaneous respiration. The mean standard errors for measurements of inflation pressure and tidal volume in the respiratory distress syndrome group during minimum positive end expiratory pressure were $0 \cdot 22$ $\mathrm{cm} \mathrm{H}_{2} \mathrm{O}$ and $0.25 \mathrm{ml}$ respectively; during positive end expiratory pressure values were $0 \cdot 13 \mathrm{~cm} \mathrm{H}_{2} \mathrm{O}$ and $0.2 \mathrm{ml}$. For the apnoea group mean standard errors for inflation pressure and tidal volume during minimum positive end expiratory pressure were 0.33 $\mathrm{cm}_{2} \mathrm{O}$ and $0.4 \mathrm{ml}$ respectively, during positive end expiratory pressure values were $0.13 \mathrm{~cm} \mathrm{H}_{2} \mathrm{O}$ and $0.2 \mathrm{ml}$ respectively.

\section{Discussion}

In this study we have tried to address two particular points relating to the use of positive end expiratory pressure in idiopathic respiratory distress syndrome. Firstly, to determine whether the use of low levels of positive end expiratory pressure, the pattern used in current clinical practice, has any important effects on blood gases. Secondly to try to gain some information on the effects of positive end expiratory pressure on the pressure/volume characteristics of the lung. We wished to make our measurements in the normal clinical settings and therefore kept the amount of handling and the number of ventilator changes carried out to a minimum. As a result of these constraints, and despite choosing seemingly stable infants, we were hampered on a number of occasions by the rapid clinical fluctuations that are commonly seen in the critically ill neonate.

We chose to present the data divided into 'breathing' and 'non-breathing' groups since respiratory efforts of any sort would obviously have affected volume and pressure measurements. We found, however, the group of infants who were not breathing spontaneously remarkably consistent on each setting, both in terms of their transcutaneous gas readings and the lung function measurements. In these infants, 'excepting the four studies in which minimum positive end expiratory pressure was not tolerated, we were able at each setting to reach a clear end point of change in transcutaneous gases with an alteration of, at most, $1 \mathrm{~mm} \mathrm{Hg}$ over six minutes (three consecutive readings). For the breathing group fluctuations of $0-3 \mathrm{~mm} \mathrm{Hg}$ after 14 minutes was accepted as a stable end point. On many occasions, however, this was not possible to achieve and hence the small size of this group. The use of transcutaneous measurements as a true reflection of changes in blood gases is now well accepted. We believe their accuracy is greatest when they are employed, as here, by a single doctor and nurse team repeatedly using the same equipment.

Similarly we are confident that the lung function measurements made in the group of infants who were not breathing spontaneously are reliable. We did not randomise our changes or routinely repeat each setting because of clinical constraints. With a group of critically ill neonates we felt it was not ethically justified to show repeatedly that a particular ventilator setting was worse than the previous one. We did, on a number of occasions, have to return from our first change to the original settings. On these occasions we found that there was very little difference between the two sets of measurements at the same settings and, in particular, compliance varied by 1 to $2 \%$ only.

Despite our doubts with regard to the group of infants who were breathing spontaneously, these babies' results all show the same trends as those of the group who were not breathing.

Many of our findings carried out in vivo are as predicted by Reyno!ds and Gribertz. ${ }^{145}$ It is interesting to note that changes in minute volume, $\mathrm{TcPO}_{2}$, and $\mathrm{TcPCO}_{2}$ occur to such a degree at levels of positive end expiratory pressure much lower than originally recommended. In four infants even these low levels seemed crucial to maintaining $\mathrm{PaO}_{2}$. Changes of the magnitude observed in these four babies presumably relate to alteration in right to left shunts. The infants ventilated for apnoea seemed to 
undergo exaggerated responses to small changes in positive end expiratory pressure. This is almost certainly a reflection of the extent to which even a low level of positive end expiratory pressure increases mean airways pressure when requirements for respiratory support had previously been minimal.

It seems true that positive end expiratory pressure will improve oxygenation in the vast majority of babies without a rise in $\mathrm{TcPCO}_{2}$ of similar magnitude. Interestingly the rise in $\mathrm{TcPCO}_{2}$ was less than that predicted from the fall in calculated alveolar ventilation. Our approximation of effective ventilation is not intended to be an accurate representation of alveolar ventilation. The fact, however, that positive end expiratory pressure in the babies with respiratory distress syndrome who were not breathing produced a mean fall of $18 \%$ in effective ventilation while $\mathrm{PCO}_{2}$ rose by only $6 \%$ implies that this manoeuvre had a beneficial effect on improving the gas exchange mechanisms within the lung.

The use of positive end expiratory pressure shifts end tidal pressure and volume points such that the compliance actually falls. This statement is based on two measurements of compliance which fulfil the accepted criteria for measurement of static compliance. For neither measurement, however, was the volume change determined using a swing between maximum pressure and atmospheric pressure but instead to a level a little above atmospheric. Such a fall in compliance has been a common finding in studies on continuous distending pressure in babies with and without respiratory diseases. ${ }^{9}$ In studies on infants with respiratory distress syndrome the fall in dynamic compliance occurring with the introduction of constant negative external pressure was thought to be due to over distension of relatively normal alveoli. ${ }^{10}$ This hypothesis did not explain the similar findings in studies on healthy term infants. ${ }^{11}$

Careful deflation pressure studies on isolated lungs of infants dying of causes other than respiratory ones have shown that even within the normal tidal range compliance is not linear. ${ }^{12}$ The shape of the pressure/volume curve is such that the expiratory limb, that is the part of the curve on which positive end expiratory pressure has its effects, undergoes maximum change in slope (compliance) at low lung volumes. Therefore, if one eliminates the high compliance, bottom end of the expiratory limb of the pressure/volume curve by the use of even small levels of constant positive airways pressure or positive end expiratory pressure compliance will inevitably be reduced.

In conclusion we feel that positive end expiratory pressure remains a useful ventilator manoeuvre, usually producing a rise in $\mathrm{Po}_{2}$ for a relatively small increase in $\mathrm{PCO}_{2}$. The efficiency is limited since the baby is then ventilated on a less compliant part of the pressure/volume curve. Whether this change is important in the production of bronchopulmonary dysplasia needs further consideration.

Similarly there is currently very little information in the preterm infant relating to the effects of positive end expiratory pressure on cardiac output. This is known to fall in adults ${ }^{13}$ after the use of positive end expiratory pressure and such a fall may be, in part, responsible for the changes we have measured.

\section{References}

${ }^{1}$ Herman S, Reynolds EOR. Methods for improving oxygenation in infants mechanically ventilated for hyaline membrane disease. Arch Dis Child 1973;48:612-7.

2 Boros SJ, Matalon SV, Ewald R, et al. The effect of independent variations in inspiratory-expiratory ratio and end expiratory pressure during mechanical ventilation in hyaline membrane disease: the significance of mean airways pressure. $J$ Pediatr 1977;91:794-8.

${ }^{3}$ Stewart. AR, Finer NN, Peters KL. Effects of alteration of inspiratory and expiratory pressures and inspiratory/expiratory ratios on mean airways pressure, blood gases and intracranial pressure. Pediatrics 1981;67:474-81.

${ }^{4}$ Gribertz I, Frank NR, Avery ME. Static volume/pressure relationships of excised lungs of infants with hyaline membrane disease, newborn and stillborn infants. $J$ Clin Invest 1959;38:216-8.

5 Reynolds EOR, Roberton NRC. Wigglesworth JS. Hyaline membrane disease, respiratory distress and surfactant deficiency. Pediatrics 1968;42:758-68.

${ }^{6}$ Huch R, Lubbers DW, Huch A. Reliability of transcutaneous monitoring of arterial $\mathrm{PO}_{2}$ in newborn infants. Arch Dis Child 1974;49:213-8.

7 Manaco F, McQuitty JC, Nickerson BG. Calibration of a heated transcutaneous carbon dioxide electrode to reflect arterial carbon dioxide. Am Rev Respir Dis 1983;127:322-4.

${ }^{8}$ Stokes GM, Milner AD, Johnson F, Hodges IGC, Groggins RC. Measurement of work of breathing in infancy. Pediatr Res 1981;15:22.

y Saunders RA, Milner AD, Hopkin IE. The effects ot continuous positive airways pressure on lung mechanics and lung volumes in the neonate. Biol Neonate 1976;29:178-86.

10 Bancalari E, Garcia O, Jesse MJ. Effects of continuous negative airways pressure on lung mechanics in the idiopathic respiratory distress syndrome. Pediatrics 1973;51:485-93.

$"$ Milner AD, Saunders RA, Hopkin IE. Effects of continuous distending pressure on lung volumes and lung mechanics in the immediate neonatal period. Biol Neonate 1977;31:111-5.

12 Fagan D. Postmortem studies on the semistatic volume/pressure characteristics of infants' lungs. Thorax 1976;31:534-43.

13 Kumar A, Falke KJ, Geffin B, et al. Continuous positive pressure ventilation in acute respiratory failure. Effects on hemodynamics and lung function. $N$ Engl J Med 1970;283: 1430-6.

14 King EG. Jones RL, Patakas DA. Evaluation of positive end expiratory pressure therapy in the adult respiratory distress syndrome. Can Anaesth Soc J 1973;20:546-58.

Correspondence to Professor A D Milner, City Hospital, Hucknall Road, Nottingham NG5 1PB.

Received 21 April 1985 